\title{
Comparative demography of commercially-harvested snappers and an emperor from American Samoa
}

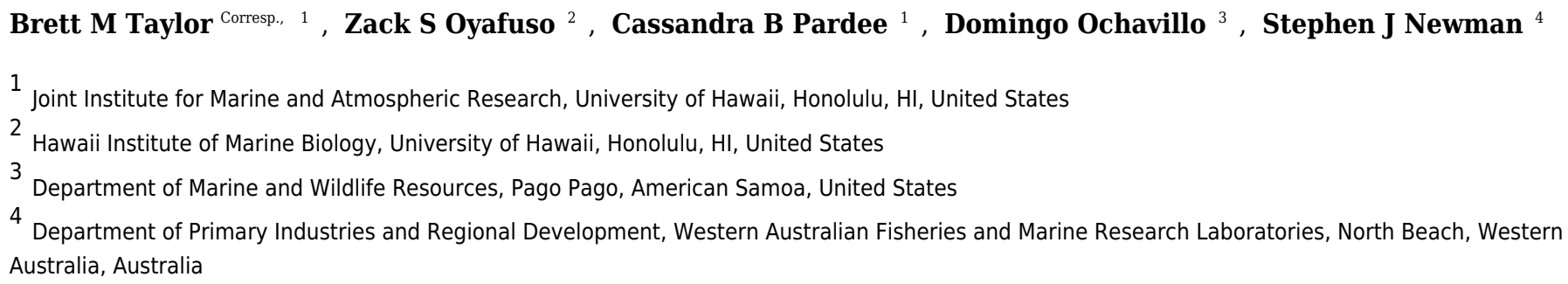

4 Department of Primary Industries and Regional Development, Western Australian Fisheries and Marine Research Laboratories, North Beach, Western Australia, Australia

Corresponding Author: Brett M Taylor

Email address: brett.taylor@noaa.gov

The age-based life history of two commercially-important species of snapper (Lutjanidae) and one emperor (Lethrinidae) were characterized from the nearshore fishery of Tutuila, American Samoa. Examination of sagittal otoliths across multiple months and years confirmed the annual deposition of increments and highlighted marked variation in lifehistory patterns among the three meso-predator species. The humpback red snapper Lutjanus gibbus is a medium-bodied gonochoristic species which exhibits striking sexual dimorphism in length-at-age and consequent growth trajectories and has a life span estimated to be at least 27 years. The yellow-lined snapper Lutjanus rufolineatus is a small-bodied gonochore with weak sexual dimorphism, early maturation, and a short life span of at least 12 years. The yellow-lip emperor Lethrinus xanthochilus is a large-bodied species with a moderate life span (estimated to be at least 19 years in this study), rapid initial growth, and a more complex sexual ontogeny likely involving pre- or postmaturational sex change, although this remains unresolved at present. Ratios of natural to fishing mortality indicate a low level of prevailing exploitation for all three species, which is supported by low proportions of immature female length classes captured by the fishery. However, considerable demographic variability among the three species highlights the value of detailed age-based information as a necessary component for informing monitoring efforts and future management decisions. 
1

2

3

4 Brett M. Taylor*1, Zack S. Oyafuso² ${ }^{\text {, Cassandra Pardee }}{ }^{1}$, Domingo Ochavillo ${ }^{3}$, Stephen J.

5

6

7 Fisheries, Pacific Islands Fisheries Science Center, Honolulu, HI, United States of America

8

\section{Comparative demography of commercially-harvested snappers and an emperor from}

\section{American Samoa}

\section{Newman $^{4}$}

${ }^{1}$ Joint Institute for Marine and Atmospheric Research, University of Hawaii and NOAA ${ }^{2}$ Hawaii Institute of Marine Biology, School of Ocean and Earth Science and Technology, University of Hawaii, Kaneohe, HI, United States of America

${ }^{3}$ Department of Marine and Wildlife Resources, Pago Pago, Tutuila, American Samoa, United States of America ${ }^{4}$ Western Australian Fisheries and Marine Research Laboratories, Department of Primary Industries and Regional Development, Government of Western Australia, WA, Australia *Corresponding author. Email: brett.taylor@noaa.gov

Phone: +1 (808) 725-5606 


\section{Abstract}

18 The age-based life history of two commercially-important species of snapper (Lutjanidae) and one emperor (Lethrinidae) were characterized from the nearshore fishery of Tutuila, American

20 Samoa. Examination of sagittal otoliths across multiple months and years confirmed the annual

21 deposition of increments and highlighted marked variation in life-history patterns among the

22 three meso-predator species. The humpback red snapper Lutjanus gibbus is a medium-bodied

23 gonochoristic species which exhibits striking sexual dimorphism in length-at-age and consequent

24 growth trajectories and has a life span estimated to be at least 27 years. The yellow-lined snapper

25 Lutjanus rufolineatus is a small-bodied gonochore with weak sexual dimorphism, early maturation, and a short life span of at least 12 years. The yellow-lip emperor Lethrinus xanthochilus is a large-bodied species with a moderate life span (estimated to be at least 19 years in this study), rapid initial growth, and a more complex sexual ontogeny likely involving pre- or post-maturational sex change, although this remains unresolved at present. Ratios of natural to fishing mortality indicate a low level of prevailing exploitation for all three species, which is supported by low proportions of immature female length classes captured by the fishery.

32 However, considerable demographic variability among the three species highlights the value of detailed age-based information as a necessary component for informing monitoring efforts and future management decisions. 


\section{Introduction}

Assemblages of snappers (Family Lutjanidae) and emperors (Family Lethrinidae) are

highly valuable components of tropical insular fisheries across the Indo-Pacific region

(Carpenter \& Allen, 1989; Dalzell, 1996; Newman, Williams \& Russ, 1997). Both families

represent meso-predator assemblages that prey on small fishes and invertebrates and are targeted

by commercial, recreational, and artisanal fishers throughout their range. The majority of species

for both families are commercially valuable and are most often harvested by line fishing

techniques in depths from shallow reef-associated habitats $(<10$ meters) to deep slopes extending to 100s of meters (Dalzell, Adams \& Polunin, 1996; Newman et al., 2016). However, in many insular locations throughout the tropics, snappers and emperors are also targeted in net and spear fisheries (Dalzell, 1996).

Life-history information underpins fisheries management in many nations. Age-based information is commonly derived from otolith-based studies, and the resultant age-based dynamics have been well-studied for both tropical snappers and emperors (e.g., Heupel et al., 2010; Currey et al., 2013). This age-based information represents a basis for guiding fisheries assessments and harvest strategies in many regions of the Indo-Pacific (Newman et al., 2016). Specific research topics include growth and mortality (Newman, Williams \& Russ 1996a; Newman, 2002; Newman, Cappo \& Williams, 2000a; 2000b; Heupel et al., 2010; Currey et al., 2013; Ebisawa \& Ozawa, 2009), reproductive biology and spawning patterns (Bannerot, Fox \& Powers, 1987; Davis \& West, 1993; Bean et al., 2003; Ebisawa, 2006; Grandcourt et al., 2010a; Heyman et al., 2005; Taylor \& Mills, 2013), and the spatial dynamics of age-based demographic variation (Newman, Williams \& Russ 1996b; Kritzer, 2002; Williams et al., 2003; Taylor \& McIlwain, 2010). Harvested species representing the families Lutjanidae and Lethrinidae are 
59 known to have moderate to high longevity, ranging from 10 to 60 years, compared with other

60

61

conspicuous reef fish taxa in tropical areas. In general, life span is positively related to body size across species for both families (Heupel et al., 2010; Taylor, Oyafuso \& Trianni 2017) and, therefore, vulnerability to overexploitation is often linked to body size.

Despite some basic commonalities between harvested snappers and emperors, the reproductive biology between these families is strikingly different. Snappers of the family Lutjanidae are, to date, unequivocally considered gonochoristic (Newman et al. 2016), whereby individuals are either male or female from earliest development and no sex change occurs throughout the life span. Ontogenetic reproductive development is much more variable across the emperors, with the dominant mode historically considered protogyny (female-to-male sex change after initial maturation as female; Young \& Martin, 1982). However, functional gonochorism through juvenile hermaphroditism is now recognized in several species (Ebisawa 2006; Marriott et al. 2010; Taylor, Oyafuso \& Trianni, 2017). Both families are generally known to spawn in aggregations that are spatially predictable and synchronized with seasonal and tidal cues (Johannes, 1978; 1981; Taylor \& Mills, 2013). Characterization of the onset and timing of maturation and reproductive activity is most accurately achieved through histological examination of gonad material throughout the calendar year. This information is of prime importance to fishery managers as an essential input to region-specific stock assessments of exploited populations.

The U.S. Pacific Island Territory of American Samoa harvests nearly 300 fish species in their nearshore reef-associated fishery. Snappers and emperors presently comprise approximately $10 \%$ of the total catch by mass (Pacific Islands Fisheries Science Center, 2018). This fact, coupled with their comparatively high market value make them an important and highly 
82 desirable component of the fishery. The prevailing status of many reef-associated populations is

83 poorly understood. The lack of appropriate catch trends and life-history data for most targeted

84 species highlights the need to evaluate the characteristics influencing a species' vulnerability to

85 overexploitation. Therefore, the purpose of this study is to derive age-based life-history

86 information from fishery-dependent collections of two snappers and one emperor of high

87 commercial value to the nearshore, reef-associated fishery of Tutuila, American Samoa. The

88 principal objectives are to estimate growth, life span, mortality, and reproductive parameters

89 based on age estimates coupled with detailed length-sampling of the commercial fishery.

90

Materials \& Methods

92

93

94

Study area and sampling protocol

Commercial reef-associated fisheries were surveyed on the island of Tutuila, American Samoa $\left(14.3^{\circ} \mathrm{S}, 170.7^{\circ} \mathrm{W}\right)$, from March 2011 to September 2015, through the NOAA Commercial Fisheries Biosampling Program (CFBP; Sundberg et al., 2015; IACUC Permit number 13-1696). Surveys were conducted from 5:30 to 8:00 am at roadside temporary vendors (typically individual or groups of fishers selling their catch from the previous night) or at the newly-established centralized fish market in Pago Pago. During sampling times, all landed fish were measured (nearest $0.1 \mathrm{~cm}$ fork length [FL]) and recorded by species. Subsamples of measured fish were purchased for life-history analysis for the following species: the yellow-lip emperor Lethrinus xanthochilus, the humpback red snapper Lutjanus gibbus, and the yellowlined snapper Lutjanus rufolineatus. These three species are common commercial and subsistence targets in the American Samoa fishery, representing the $9^{\text {th }}, 12^{\text {th }}$, and $66^{\text {th }}$ most common species by mass, respectively, in the nearshore catch out of nearly 300 harvested 
105 species (Pacific Islands Fisheries Science Center, 2018). Purchased fish were selected non-

106 randomly to encompass all length classes targeted by the fishery. For each purchased specimen,

107 samplers measured length (nearest $0.1 \mathrm{~cm} \mathrm{FL)}$ and total body mass (g). Sagittal otoliths and

108 gonad lobes were surgically extracted from each specimen for age and reproductive assessment.

109 Otoliths were cleaned with ethanol and stored dry in individually labeled vials. Gonads were

110 weighed to the nearest $0.001 \mathrm{~g}$ and macroscopically designated by sex. Entire gonad lobes or

111 cross sections ( $3 \mathrm{~mm}$ thick) of gonad material from the mid-sections of gonad lobes were

112 removed and stored using individually-labeled histological cassettes in a $10 \%$ buffered formalin

113 solution.

114

115 Age determination and growth

116 For the three species, one sagittal otolith from each specimen was selected at random and

117 affixed to a glass slide using thermoplastic glue (Crystalbond $509^{\circledR}$ ), such that the primordium

118 was focused just inside the edge of the slide, and the sulcul ridge was perpendicular to the slide

119 edge. The otolith was ground to the slide edge using a 600-grit diamond lapping wheel with

120 continuous water flow along the longitudinal axis until flush with the edge of the slide. The

121 otolith was then removed with heat $\left(\sim 200^{\circ} \mathrm{C}\right)$ and reaffixed with the newly flat surface down and

122 ground to produce a thin $(\sim 250 \mu \mathrm{m})$ transverse section encompassing the core material. Annuli,

123 represented by alternating translucent and opaque bands, were counted along a consistent axis on

124 the face of the sections to derive an estimate of age in years. Using reflected light ( $L$.

125 xanthochilus) and transmitted light (L. gibbus and L. rufolineatus) on a stereomicroscope, age

126 readings for all specimens were conducted on three separate occasions by the primary author and

127 final age (number of annuli as a proxy for age in years) was assigned when agreement in counts 
128 occurred. If three counts differed by one presumed annulus (e.g., 13, 12, 14), the middle age was

129 assigned (e.g., 13). Daily growth increments were enumerated for one small $(10.1 \mathrm{~cm})$ specimen

130 of L. xanthochilus with preparation and reading protocols following Taylor \& Choat (2014).

131 Daily growth increment profiles of recently recruited L. xanthochilus were first summarized in

132 Wilson and McCormick (1999).

133 The assumption that annuli are deposited on a yearly cycle was tested using edge-type

134 analysis for each species (Manickchand-Heileman and Phillip, 2000). The outermost otolith

135 margin was scored as within either an opaque or translucent zone across all specimens, and

136 proportions of opaque zone deposition were plotted across the calendar year for each species.

137 Plots were presented alongside annual patterns of sea surface temperature, using remotely sensed

138 data (1-day resolution, Pathfinder data base available through NOAA Coastwatch, Jan 2006

139 through May 2011).

140 Sex-specific patterns of growth were modeled by fitting the von Bertalanffy growth

141 function (VBGF) to length-at-age data using least squares estimation. The VBGF is represented

142 by:

$$
L_{t}=L_{\infty}\left[1-e^{-K\left(t-t_{0}\right)}\right]
$$

144 where $L_{t}$ represents the predicted mean FL (cm) at age $t$ (years), $L_{\infty}$ is the mean asymptotic FL,

$145 K$ is the coefficient used to describe the curvature of fish growth towards $L_{\infty}$, and $t_{0}$ is the

146 hypothetical age at which FL is equal to zero, as described by K. As the sampling protocol was

147 fisheries-dependent, very few specimens were below the $15-20 \mathrm{~cm}$ range. Hence, to approximate

148 early growth trajectories, VBGF models were constrained to an established or inferred (from

149 similar taxa) length at settlement (i.e., FL at age 0). For L. xanthochilus, this was $3.0 \mathrm{~cm}$ 
150 (Nakamura et al., 2010); for L. gibbus and L. rufolineatus, this was $3.5 \mathrm{~cm}$ (Mori, 1984; Nanami

151 \& Yamada, 2009).

152

153 Mortality

154 Total mortality $(Z)$ was estimated using a multinomial catch curve fitted to the age classes

155 at or above the assumed age at full recruitment to the fishery $\left(t_{r e c}\right) \cdot t_{r e c}$ is defined as one plus the

156 peak frequency age (Dunn, Francis \& Doonan, 2002). For fish at or above $t_{r e c}$, the per recruit

157 survival of fish $\left(S_{t}\right)$ to integer age $(t)$ was calculated as:

158

$$
S_{t}=e^{-Z\left(t-t_{r e c}\right)}
$$

${ }_{P}^{t}$, the expected proportion of fully-recruited fish at age $t$ was calculated as:

160

$$
\hat{P}^{t}=\frac{S_{t}}{\sum_{t=t_{\text {rec }}}^{t_{\max }} S_{t}}
$$

161 where $t_{\max }$ refers to the maximum observed age. The catch curve was fitted by maximizing the multinomial log-likelihood $(\lambda)$ associated with the observed and expected proportions at age:

$$
\lambda=\sum_{t=t_{r e c}}^{t_{\max }} f_{t} \ln \left({ }_{P}{ }^{t}\right)
$$

where $f_{t}$ refers to the observed frequency at age $t$.

The value for the natural mortality (assumed constant across age) in this analysis was

166 calculated using the Hoenig (1983) equation: $Z=\mathrm{e}^{1.46-1.01 * \log \left(t_{\max }\right)}$, whereby $Z$ is equal to $M$

167 through this derivation if the true maximum age was derived. For empirical derivations of $M$ in

168 this study, we cautiously assumed this to be true. 

bootstrap procedure. The proportion in each length bin (5-cm bin width) from the full size

171 distribution from the fishery was calculated and used as weights in the bootstrap resampling of

172 the length-age samples. For example, if the sample size of the length-age data was 100 and the

173 proportion of individuals in the first length bin in the full size distribution was 0.05 , five data

174 points from the first length bin in the length-age data were sampled with replacement. With the 175 exception of a small individual in the L. xanthochilus dataset $(10.1 \mathrm{~cm}, 0.35$ years old [estimated 176 based on daily growth increments]), the length ranges of the length-age data were similar to 177 those from the full length distribution of the fishery. Each dataset was bootstrapped 10,000 178 times. The median of the bootstrap distribution was reported and the $2.5^{\text {th }}$ and $97.5^{\text {th }}$ percentiles 179 of the bootstrap distribution of total mortality were reported as the $95 \%$ percentile confidence interval. The sensitivity of the size of the length bins on the total mortality estimate was evaluated using length bins of 2, 5, 10, and $20 \mathrm{~cm}$, and also across individual years to examine potential effects of compounding multi-year data. The total mortality estimate using a conventional bootstrap was also evaluated as a part of the sensitivity analysis. This lengthstratified bootstrap method was used because our sampling program was not designed to derive a random sample representative of the fishery, whereas the full market survey was designed for this purpose. Additionally, all otoliths and gonads that were originally sampled were not retained 187 for final processing, which further precluded us from considering the sample to be 188 representative. 
192 School of Medicine at the University of Hawaii. Sections were imbedded in paraffin wax, 193 sectioned transversely at $6 \mu \mathrm{m}$, and stained on microscope slides with haematoxylin and eosin.

194 Slides were viewed under dissecting and compound microscopes with transmitted light to 195 determine sex and level of reproductive development following criteria and terminology from

196 Brown-Peterson et al. (2011). The female maturation schedule by length and age was modeled 197 for each species. Specimens were scored by their maturity status (immature, 0: representing 198 'Immature' and 'Developing' phases from Brown-Peterson et al., 2011; mature, 1: representing 199 'Spawning capable,' 'Regressing,' and 'Regenerating'), and maturity-at-length/age data were 200 fitted with a two-parameter logistic curve as follows:

$201 P_{L}=\left\{1+e^{-\ln (19)\left(L-L_{50}\right) /\left(L_{95}-L_{50}\right)}\right\}^{-1}$

202 where $P_{L}\left(P_{t}\right.$ for age at maturity) is the estimated proportion of mature females at a given length $203(L)$, and $L_{50}$ and $L_{95}\left(t_{50}\right.$ and $t_{95}$ for age) are the FL at 50 and $95 \%$ maturity, respectively.

204 Corresponding 95\% confidence limits (CLs) for the maturity schedules were derived by 205 bootstrap resampling with replacement through 1,000 iterations.

206

Although not a primary objective of this study, we further examined aspects of the 207 reproductive developmental ontogeny of L. xanthochilus based on histological features of 208 specimens and length- and age-based patterns of sex ratio. Specifically, we searched for evidence 209 of pre- or post-maturational female-to-male sex change, as has been commonly identified in 210 species of Lethrinus, following criteria established in Sadovy \& Shapiro (1987) and Sadovy de 211 Mitcheson \& Liu (2008). 
214 Age determination and growth

215 From March 2011 to September 2015, a total of 2559, 2788, and 847 commercial

216 specimens were measured of L. xanthochilus, L. gibbus, and L. rufolineatus, respectively. Of

217 these, 372 L. xanthochilus, 481 L. gibbus, and 217 L. rufolineatus were dissected for life-history

218 analysis, but otoliths and/or gonads were retained for only 244, 311, and 149 individuals,

219 respectively. Length-frequency distributions from the commercial harvest are displayed in Fig. 1.

220 All species showed unimodal distributions with modal fork length bins of 38.5, 27.5, and 21.5

$221 \mathrm{~cm}$, respectively. However, L. gibbus displayed a considerable second 'hump' in the size

222 distribution at $36.5 \mathrm{~cm}$. Ages were estimated from sagittal otoliths from a total of 236 specimens

223 for both L. xanthochilus and L. gibbus and from 134 specimens for L. rufolineatus (Table 1).

224 Although no species were sampled through all calendar months, annual patterns of edge

225 deposition demonstrated an annual periodicity in the formation of opaque zones, confirming that

226 increments are indeed annual (Fig. 2, Supplemental Information). Opaque zones were fully

227 deposited in August-September during peak low sea surface temperatures in American Samoa.

228 All three species deposited clearly defined annuli that were highly characteristic of otolith

229 patterns previously identified for snappers or emperors (Fig. 3A-C; e.g., Marriott and Mapstone

230 2006; Grandcourt, Al Abdessalaam \& Al Shamsi, 2010b). Otolith weight was a strong predictor

231 for age in all species, whereby relationships were best explained using a standard quadratic

232 equation (Fig. 4). The relationship between otolith weight and age did not differ between males

233 and females for L. xanthochilus or L. rufolineatus, but it differed substantially between the sexes

234 for L. gibbus (Fig. 4B). This pattern was retained in the length-at-age derived growth profiles,

235 whereby patterns of growth were nearly identical between the sexes for L. xanthochilus and $L$.

236 rufolineatus. Growth profiles diverged between males and females for L. gibbus, with males 
237 reaching a much larger asymptote (difference of $\sim 10 \mathrm{~cm}$; Fig. 5; values in Table 1). Overall

238 VBGF parameter values $L_{\infty}$ and $K$ for the combined sexes were as follows: $L$. xanthochilus, $L_{\infty}=$ $40.2 \mathrm{~cm}, K=0.64 \mathrm{yr}^{-1} ;$ L. gibbus, $L_{\infty}=32.9 \mathrm{~cm}, K=0.46 \mathrm{yr}^{-1} ;$ L. rufolineatus, $L_{\infty}=22.9 \mathrm{~cm}, K=$

$2400.82 \mathrm{yr}^{-1}$. Sex-specific VBGF values and associated confidence limits are presented in Table 1.

241 Sex-specific maximum observed ages for each species were 12 and 19 years for female and male

242 L. xanthochilus, respectively, 27 and 19 years for female and male L. gibbus, and 8 and 12 years

243 for female and male L. rufolineatus.

245 Mortality

Median total mortality estimates were 0.35 (95\% percentile CI: $0.29-0.41), 0.22$ (95\%

percentile CI: 0.19-0.26), and 0.54 (95\% percentile CI: 0.44-0.75) for L. xanthochilus, L. gibbus, and L. rufolineatus based on data pooled across surveyed years (Fig. 6). The estimate for total mortality and the distribution of total mortality bootstrapped estimates were sensitive to neither the size of the length bin, nor to the type of bootstrap procedure or timeframe (annual versus pooled) of survey data (Supplemental Information). Estimates from individual years were consistent and slightly higher than for pooled years for L. xanthochilus alone. The distributions of bootstrapped total mortality estimates were approximately symmetric for the L. xanthochilus and $L$. gibbus datasets, while the distribution of bootstrapped total mortality estimates for $L$. rufolineatus had a slight positive skew (Figure 6C). Estimated natural mortality rates were 0.22, 0.15, and 0.35 year $^{-1}$ for L. xanthochilus, L. gibbus, and L. rufolineatus, suggesting fishing mortality rates were approximately half the presumed natural mortality across species. 

covered the length and age ranges over which female maturation occurred for L. xanthochilus and L. gibbus. Length at maturation (but not age) was modelled for L. rufolineatus based on only years $(1.8-2.3$ years $95 \%$ C.L. $)$ for L. xanthochilus and 3.2 years $(2.9-3.9$ years 95\% C.L.) for L. gibbus (Fig. 7D-E). contained internal parasites. We found one specimen $(39 \mathrm{~cm} \mathrm{FL})$ that contained an atretic vitellogenic oocyte in the presence of proliferating male material, indicating post-maturational sex change (functional protogyny). This specimen also had large gonad walls and displayed tight rounded folds of the epithelium (Fig. 8). Testes of other specimens were found to be in similar condition - presumed to be in a transitional mode - but did not contain identifiable atretic oocytes. Further, we found at least two potentially bisexual individuals (both aged 2 years) under or near the size at first female maturation (24.0 and 29.4 cm FL; Fig. 9), indicating primary development into males. In both cases, primary oocytes were sparse (compared with other immature females), and stromal tissue proliferated with tenuous evidence of sperm crypt 
283 development. Length-based and age-based relative proportions of females and males across

284 length and age classes provided further evidence of both pre- and post-maturational sex change

285 (Supplemental Information). It is clear that sex ratios change considerably across size and age

286 classes and that some females are retained in the largest length classes, but more robust

287 investigations are required to determine developmental ontogeny for this species.

Discussion

Compared with other harvested families in tropical fisheries globally, lutjanids and

lethrinids are among the most studied on coral reefs with regard to life-history information as a necessary input for fisheries management. The information presented in this study provides detailed demographic profiles for three commercially-important meso-predators that differ markedly in terms of their trait values and life-history patterns. L. gibbus is a comparatively medium-bodied gonochoristic species that has clear sexual dimorphism, and a long life span. $L$. rufolineatus is a small-bodied gonochore that has weak sexual dimorphism and a short life span. L. xanthochilus is a large-bodied species with a moderate life span and has a more complex sexual ontogeny likely involving pre- and post-maturational sex change. Hence, it is prudent to assume that responses to selective fishery harvest will differ among the three species. For instance, larger body size and longer life span are commonly associated with greater vulnerability to overexploitation (Abesamis et al., 2014). The influence of differing reproductive strategies on species' vulnerability is less clear. relative to the rate of natural mortality in American Samoa, with the vast majority of harvested fishery specimens greater than the median length at female maturation for each species. 
306 Estimated total mortality was derived using a length-stratified bootstrapping procedure which

307 was robust to potential sampling bias for age-based data because it resampled age-at-length data

308 to match the larger and unbiased market survey length distributions. The uncertainty surrounding

309 estimates of total mortality decreased with increasing life span (i.e., number of data points

310 yielding mortality curves) across species, but we caution the use of this method with L. gibbus,

311 the longest lived species. This species demonstrated pronounced sexually dimorphic growth with

312 males reaching a much larger length-at-age than females. Hence, the structure of length-

313 frequency distributions is highly sex-specific, potentially yielding more variable age-frequency

314 distributions when derived from age-length relationships based on pooled sexes. The data herein

315 should be used in comprehensive stock assessments to fully explore the relative sustainability of

316 extant fisheries. However, further simulation testing should first be conducted to understand the

317 robustness of mortality estimates under different sampling designs and life-history traits using

318 the length-stratified bootstrapping procedure.

319 To date, little age-based or reproductive information is available for the three species

320 examined here. The most comprehensive description is for L. gibbus from Okinawa (Nanami et

321 al., 2010), which documented life span, growth, and reproductive seasonality for the region

322 based on fishery-dependent sampling. Sex-specific maximum ages and growth profiles from

323 Okinawa were similar to those observed from American Samoa. Nanami et al. (2010) found that

324 L. gibbus had a long ( 6 month) spawning period which occurred during the warmer part of the

325 year, whereby subsequent settlement of recruiting juveniles was synchronized with lunar cycles.

326 Johannes (1981) documented from the accounts of fishers in Palau that L. gibbus spawns around

327 full moon throughout the year. Considerable differences in the growth profile and maximum age

328 of L. gibbus were identified from the GBR (Heupel et al., 2010), although this study reported 
329 concerns regarding undersampling of both the smallest and largest (and presumably oldest) size

330 classes. Loubens (1980) reported a maximum age estimate of only 18 years for L. gibbus in the

331 waters of New Caledonia based on counts of annuli in sectioned otoliths, much less than the

332 maximum age estimate derived from this study. For L. rufolineatus, Mizenko (1984) documented

333 evidence for seasonal reproductive activity in Samoa during autumn and winter with spawning

334 taking place around full moon. Similar to our study, Mizenko (1984) found very few fish with

335 immature ovaries above $17 \mathrm{~cm}$, thus confirming our small estimate of length at maturity despite

336 low sample sizes in the smallest length classes. We found no existing age-based or reproductive

337 information for L. xanthochilus in the primary literature. Sample sizes of females across the

338 annual and lunar calendar in the present study were not sufficient to determine reproductive

339 periodicity. However, distinct post-ovulatory follicles were present for all species at various

340 times during the year in mature females, suggesting that each species has an extended

341 reproductive period.

342 Our results suggest a diandric protogynous life-history mode for L. xanthochilus.

343 However, based on our relatively small sample size and limited evidence, we do not consider our

344 results to be definitive regarding the reproductive ontogeny of this species in American Samoa.

345 Most lethrinids are recognized as either functional protogynous hermaphrodites or juvenile

346 hermaphrodites (Ebisawa, 2006). We recognized two potential pathways for male recruitment,

347 pre-maturational and through sex transition from functionally mature females. Post-maturational

348 male development was supported by length- and age-based schedules of sex ratio. The length-

349 based schedule suggests that females occur into the largest length classes, and appears

350 confounded by potential primary males (i.e., individuals that develop first as males). However,

351 length-based schedules of sex change can be confounded by sexually-dimorphic growth, which 
352 was limited in L. xanthochilus. The age-based schedule demonstrates much clearer evidence of

353 sexual transition from female to male as a cohort ages. Ultimately, length-based schedules of sex

354 change are rarely clear cut for lethrinid species (Ebisawa, 2006) compared with prominent

355 protogynes, such as labrids, that have dichromatism and seemingly much more complex social-

356 reproductive systems centered on size-based defense of territories (e.g., Taylor \& Choat, 2014).

357 Pronounced sexual dimorphism does not appear to be prevalent among the snappers, but

358 considerable differences in asymptotic lengths between males and females have been observed

359 for several species (Newman, Cappo \& Williams, 2000a; Newman, 2002; Shimose \& Tachihara,

360 2005). Here, differences in size-at-age between male and female L. gibbus matched observations

361 previously documented from Japan for the species (Nanami et al., 2010) and represent the largest

362 disparity in male versus female size in any snapper species to date. The ecological context of

363 sexual dimorphism is hinged on assumptions that female size reflects a trade-off between growth

364 and fecundity, and male size is influenced by reproductive competition (Parker, 1992). Based on

365 the ubiquity of absent or weak sexual dimorphism in the snappers, we must presume that $L$.

366 gibbus populations have an unusually different reproductive ecology compared with other

367 lutjanids to yield such stark differences. Further, this level of dimorphism can complicate

368 assessments of population status, especially when the primary data source is abundance and

369 length-frequencies from fishery-dependent or independent surveys. We note that the frequency

370 distribution presented in Fig. 1 for L. gibbus was bimodal, with primary and secondary peaks

371 closely corresponding with asymptotic lengths of females and males. This highlights the

372 importance of understanding how sex-specific growth trajectories influence sex ratios across

373 length classes at the population level. 


\section{Conclusions}

376 Snapper and emperor species have historically been a highly-valued component of coral reef-

377 associated fishes. Our results provide key population-level trait values that are of significant

378 utility to stock assessment and fishery management. In doing so, we highlight differences in the

379 biology and associated recovery potential of three phylogenetically-related species commonly

380 harvested by the same methods during the same fishing trips.

381

382 Acknowledgements

383 The authors thank the American Samoa Biosampling Team for their efforts in the field and R

384 Nichols, E Reed, and K Rhodes for additional interpretations and discussions of gonad histology.

385 Constructive comments by Tiffany Sih, Bill Duffy, and an anonymous reviewer greatly

386 improved the manuscript. All data used in this publication are from

387 https://inport.nmfs.noaa.gov/inport/item/5619. 
388

389

390

391

392

393

394

395

396

397

398

399

400

401

402

403

404

405

406

407

408

409

\section{References}

Abesamis RA, Green AL, Russ GR, Jadloc CRL. 2014. The intrinsic vulnerability to fishing of coral reef fishes and their differential recovery in fishery closure. Reviews in Fish Biology and Fisheries 24: 1033-1063. DOI: 10.1007/s11160-014-9362-x.

Bannerot S, Fox Jr WW, Powers JE. 1987. Reproductive strategies and the management of snappers and groupers in the Gulf of Mexico and the Caribbean. In: Polovina, J. J., Ralston, S. (Eds.), Tropical snappers and groupers: biology and fisheries management. Westview Press, Boulder, Colorado.

Bean K., Mapstone BD, Davies CR, Murchie CD, Williams AJ. 2003. Gonad Development and evidence of protogyny in the red-throat emperor on the Great Barrier Reef. Journal of Fish Biology 62: 299-310. DOI: 10.1046/j.1095-8649.2003.00021.x.

Brown-Peterson NJ, Wyanski DM, Saborido-Rey F, Macewicz BJ, Lowerre-Barbieri SK. 2011. A standardized terminology for describing reproductive development in fishes. Marine and Coastal Fisheries 3: 52-70. DOI: 10.1080/19425120.2011.555724.

Carpenter KE, Allen GR. 1989. FAO species catalogue. Emperor fishes and large-eyed breams of the world (Family Lethrinidae). FAO Fisheries Synopsis No. 125 9, 118 p.

Currey LM, Williams AJ, Mapstone BD, Davies CR, Carlos G, Welch DJ, Simpfendorfer CA, Ballagh AC, Penny AL, Grandcourt EM, Mapleston A, Wiebkin AS, Bean K. 2013. Comparative biology of tropical Lethrinus species (Lethrinidae): challenges for multispecies management. Journal of Fish Biology 82: 764-788. DOI: 10.1111/jfb.3495.

Dalzell P. 1996. Catch rates, selectivity and yields of reef fishing. In: Polunin, N.V.C., Roberts, C.M. (Eds.), Reef Fisheries. Chapman and Hall, London. Pp. 161-192. 
410 Dalzell P, Adams TJH, Polunin NVC. 1996. Coastal fisheries in the Pacific islands.

411 Oceanography and Marine Biology: an Annual Review 34: 395-531.

412 Davis TLO, West GJ. 1993. Maturation, reproductive seasonality, fecundity, and spawning

413 frequency in Lutjanus vittus (Quoy and Gaimard) from the North West Shelf of Australia.

$414 \quad$ Fishery Bulletin 91: 224-236.

415 Dunn A, Franciss RICC, Doonan IJ. 2002. Comparison of the Chapman-Robson and regression 416 estimators of $Z$ from catch-curve data when non-sampling stochastic error is present.

417 Fisheries Research 59: 149-159. DOI: 10.1016/S0165-7836(01)00407-6.

418 Ebisawa A. 2006. Reproductive and sexual characteristics in five Lethrinus species in waters off the Ryukyu Islands. Ichthyological Research 53: 269-280. DOI: 10.1007/s10228-0060345-3.

421

422

423

424

425

426

427

428

429

430

431

Ebisawa A, Ozawa T. 2009. Life-history traits of eight Lethrinus species from two local populations in waters off the Ryukyu Islands. Fisheries Science 75: 553-566. DOI: 10.1007/s12562-009-0061-9.

Grandcourt EM, Al Abdessalaam TZ, Francis F, Al Shamsi T. 2010a. Reproductive biology and implications for management of the spangled emperor Lethrinus nebulosus in the southern Arabian Gulf. Journal of Fish Biology 77: 2229-2247. DOI: 10.1111/j.10958649.2010.02799.x.

Grandcourt EM, Al Abdessalaam TZ, Al Shamsi AT. 2010b. Age-based life history parameters and status assessments of by-catch species (Lethrinus borbonicus, Lethrinus microdon, Pomacanthus maculosus and Scolopsis taeniatus) in the southern Arabian Gulf. Journal of Applied Ichthyology 26: 381-389. DOI: 10.1111/j/1439-0426.2009.01380.x. 
432 Heupel MR, Penny A, Williams AJ, Kritzer JP, Welch DJ, Marriott RJ, Davies CR, Mapstone 433 BD. 2010. Demographic characteristics of exploited tropical lutjanids: a comparative

434

435

436

437

438

439

440

441

442

443

444

445

446

447

448

449

450

451

452

453

454

analysis. Fishery Bulletin 108: 420-432.

Heyman WD, Kjerfve B, Graham RT, Rhodes KL, Garbutt L. 2005. Spawning aggregations of Lutjanus cyanopterus (Cuvier) on the Belize Barrier Reef over a 6 year period. Journal of Fish Biology 67: 83-101. DOI: 10.1111.j.0022-1112.2005.00714.x.

Hoenig JM. 1983. Empirical use of longevity data to estimate mortality rates. Fishery Bulletin 82: 898-903.

Johannes RE. 1978. Reproductive strategies of coastal marine fishes in the tropics. Environmental Biology of Fishes 3: 65-84. DOI: 10.1007/BF00006309.

Johannes RE. 1981 Words of the Lagoon: Fishing and Marine Lore in the Palau District of Micronesia. University of California Press, Los Angeles.

Kritzer JP. 2002. Variation in the population biology of the stripey bass Lutjanus carponotatus within and between two island groups on the Great Barrier Reef. Marine Ecology Progress Series 243: 191-207. DOI: 10.3354/meps243191.

Loubens G. 1980. Biologie de quelques especes de poissons du lagon Neo-Caledonian. III. Croissance. Cahiers de l'Indo-Pacifique 2: 101-153.

Marriott RJ, Mapstone BD. 2006. Geographic influences on and the accuracy and precision of age estimates for the red bass, Lutjanus bohar (Forsskal 1995): A large tropical reef fish. Fisheries Research 80: 322-328. DOI:

Manickchand-Heileman SC, Phillip DAT. 2000. Age and growth of the yellowedge grouper, Epinephelus flavolimbatus, and the yellowmouth grouper, Mycteroperca interstitialis, off Trinidad and Tobago. Fishery Bulletin 98: 290-298. 
455 Marriott RJ, Jarvis NDC, Adams DJ, Gallash AE, Norriss J, Newman SJ. 2010. Maturation and 456 sexual ontogeny in the spangled emperor Lethrinus nebulosus. Journal of Fish Biology. 76

457

458

459

460

461

462

463

464

465

466

467

468

469

470

471

472

473

474

475

476

(6): 1396-1414. DOI: 10.1111/j.1095-8649.2010.02571.x.

Mizenko D. 1984. The biology of Western Samoan reef-slope snapper (Pisces: Lutjanidae) populations of: Lutjanus kasmira, Lutjanus rufolineatus, and Pristipomoides multidens. MS thesis, University of Rhode Island, Kingston, Rhode Island.

Mori K. 1984. Early life history of Lutjanus vitta (Lutjanidae) in Yuya Bay, the Sea of Japan. Japanese Journal of Ichthyology 30: 374-392. DOI: 10.11369/jji1950.30.374.

Nakamura Y, Shibuno T, Suzuki N, Nakamori J, Kanashiro K, Watanabe Y. 2010. Interspecific variations in age and size at settlement of 8 emperor fishes (Lethrinidae) at the southern Ryukyu Islands, Japan. Fisheries Science 76: 503-510. DOI: 10.1007/s12562-010-0225-7.

Nanami A, Yamada H. 2009. Seasonality, lunar periodicity of settlement and microhabitat association of juvenile humpback red snapper Lutjanus gibbus (Lutjanidae) in an Okinawan coral reef. Marine Biology 156: 407-414. DOI: 10.1007/s00227-008-1093-x.

Nanami A, Kurihara T, Kurita Y, Aonuma Y, Suzuki N, Yamada H. 2010. Age, growth and reproduction of the humpback red snapper Lutjanus gibbus off Ishigaki Island, Okinawa. Ichthyological Research 57: 240-244. DOI: 10.1007/s10228-010-0160-8.

Newman SJ. 2002. Growth rate, age determination, natural mortality and production potential of the scarlet seaperch, Lutjanus malabaricus Schneider 1801, off the Pilbara coast of northwestern Australia. Fisheries Research 58: 215-225. DOI: 10.1016/S0165-7836(01)00367-8.

Newman SJ, Williams DMcB, Russ GR. 1996a. Age validation, growth and mortality rates of the tropical snappers (Pisces: Lutjanidae), Lutjanus adetii (Castelnau, 1873) and L. 
477

478

479

480

481

482

483

484

485

486

487

488

489

490

491

492

493

494

495

496

497

498

499

quinquelineatus (Bloch, 1790) from the central Great Barrier Reef, Australia. Marine and Freshwater Research 47: 575-584. DOI: 10.1071/MF9960575.

Newman SJ, Williams DMcB, Russ GR. 1996b. Variability in the population structure of Lutjanus adetii (Castelnau, 1873) and L. quinquelineatus (Bloch, 1790) among reefs in the central Great Barrier Reef, Australia. Fishery Bulletin 94: 313-329.

Newman SJ, Williams DMcB, Russ GR. 1997. Patterns of zonation of assemblages of the Lutjanidae, Lethrinidae and Serranidae (Epinephelinae) within and among mid-shelf and outer-shelf reefs in the Central Great Barrier Reef. Marine and Freshwater Research 48: 119-128. DOI: 10.1071/MF96047.

Newman SJ, Cappo M, Williams DMcB. 2000a. Age, growth and mortality of the stripey, Lutjanus carponotatus (Richardson) and the brown-stripe snapper, L. vitta (Quoy and Gaimard) from the central Great Barrier Reef, Australia. Fisheries Research 48: 263-275. DOI: $10.1016 / \mathrm{S} 0165-7836(00) 00184-3$.

Newman SJ, Cappo M, Williams DMcB. 2000b. Age, growth, mortality rates and corresponding yield estimates using otoliths of the tropical red snappers, Lutjanus erythropterus, L. malabaricus and L. sebae, from the central Great Barrier Reef. Fisheries Research 48: 114. DOI: $10.1016 / \mathrm{S} 0165-7836(00) 00115-6$.

Newman SJ, Williams AJ, Wakefield CB, Nicol SJ, Taylor BM, O’Malley JM. 2016. Review of the life history characteristics, ecology and fisheries for deep-water tropical demersal fish in the Indo-Pacific region. Reviews in Fish Biology and Fisheries 26: 537-562. DOI: 10.1007/s11160-016-9442-1.

Parker GA. 1992. The evolution of sexual size dimorphism in fish. Journal of Fish Biology 41(Supplement B): 1-20. DOI: 10.1111/j.1095-8649.1992.tb03864.x. 
500 Sadovy Y, Shapiro DY. 1987. Criteria for the diagnosis of hermaphroditism in fishes. Copeia $501 \quad$ 1987: 136-156. DOI: 10.2307/1446046.

502 Sadovy de Mitcheson Y, Liu M. 2008. Functional hermaphroditism in teleosts. Fish and $503 \quad$ Fisheries 9: 1-43. DOI: 10.1111/j.1467-2979.2007.00266.x.

504 Shimose T, Tachihara K. 2005. Age, growth and maturation of the blackspot snapper Lutjanus 505 fulviflammus around Okinawa Island, Japan. Fisheries Sci 71: 48-55. DOI: 10.1111/j.1444$506 \quad 2906.2005 .00929 . x$.

507 Sundberg M, Humphreys R, Lowe MK, Cruz E, Gourley J, Ochavillo D. 2015. Status of Life 508 History Sampling Conducted through the Commercial Fisheries Bio-sampling Programs in 509 the Western Pacific Territories of American Samoa and Guam and in the Commonwealth 510 of the Northern Mariana Islands. NOAA Administrative Report H-15-08, 56 pp.

511 Taylor BM, McIlwain JL. 2010. Beyond abundance and biomass: effects of marine protected 512 areas on the demography of a highly exploited reef fish. Marine Ecology Progress Series 411: 243-258. DOI: 10.3354/meps08672.

514 Taylor BM, Mills JS. 2013. Movement and spawning migration patterns suggest small marine 515 reserves can offer adequate protection for exploited emperorfishes. Coral Reefs 32: 10771087. DOI: $10.1007 / \mathrm{s} 00338-013-1065-6$.

517 Taylor BM, Choat JH. 2014. Comparative demography of commercially important parrotfish 518 species from Micronesia. Journal of Fish Biology 84: 383-402. DOI: 10.1111/jfb.12294.

519 Taylor BM, Oyafuso ZS, Trianni MS. 2017. Life history of the orange-striped emperor Lethrinus 520 obsoletus from the Mariana Islands. Ichthyological Research 64: 423-432. DOI:

521 10.1007/s10228-017-0573-8. 
522 Williams AJ, Davies CR, Mapstone BD, Russ GR. 2003. Scales of spatial variation in

523 demography of a large coral-reef fish - an exception to the typical model? Fishery Bulletin $524 \quad 101: 673-683$.

525 Wilson DT, McCormick MI. 1999. Microstructure of settlement-marks in the otoliths of tropical 526 reef fishes. Marine Biology 134: 29-41. DOI: 10.1007/s002270050522.

527 Young PC, Martin RB. 1982. Evidence for protogynous hermaphroditism in some lethrinid 528 fishes. Journal of Fish Biology 21: 475-484. DOI: 10.1111/j.1095-8649.1982.tb02853.x.

529

530

Electronic references

531 Pacific Islands Fisheries Science Center. 2018. American Samoa Commercial Fisheries

532 BioSampling (CFBS), http://inport.nmfs.noaa.gov/inport/item/5619.

533 


\section{Figure captions}

535 Figure 1. Length-frequency distrbutions derived from the Tutuila-based, American Samoa 536 commercial fishery from 2011-2015 for (A) Lethrinus xanthochilus, (B) Lutjanus gibbus, and

537 (C) Lutjanus rufolineatus. Total number of samples recorded are presented for each species.

538 Figure 2. Frequency of opaque edge deposition by month in transverse sections of otoliths from

539 three commercial species from Tutuila, American Samoa. The continuous grey line displays

540 mean daily sea surface temperature across the calendar year based on satellite-derived data from

541 Jan 2006 to May 2011.

542 Figure 3. Photomicrographs of transverse otolith sections for (A) Lethrinus xanthochilus

543 (reflected light), (B) Lutjanus gibbus (transmitted light), and (C) Lutjanus rufolineatus

544 (transmitted light). Annual increments (opaque bands) are denoted by white boxes, with the

545 inset in (B) providing greater resolution for smaller increments.

546 Figure 4. Sex-specific relationships between sagittal otolith weight (g) and annual age (as

547 number of annuli) for (A) Lethrinus xanthochilus, (B) Lutjanus gibbus, and (C) Lutjanus

548 rufolineatus from Tutuila, American Samoa. Equations are as follows: L. xanthochilus, male age

$549=0.3+20.2 *($ Otolith weight $)+247.3 *(\text { Otolith weight })^{2}$, female age $=0.9+11.8 *($ Otolith

550 weight $)+253.2 *(\text { Otolith weight })^{2} ;$ L. gibbus, male age $=0.5+27.0 *($ Otolith weight $)+$

$551444.0 *(\text { Otolith weight })^{2}$, female age $=-0.5+47.4 *($ Otolith weight $)+130.3 *(\text { Otolith weight })^{2} ; L$.

552 rufolineatus, male age $=-1.0+25.8 *($ Otolith weight $)+21.1 *(\text { Otolith weight })^{2}$, female age $=-1.1$

$553+33.1 *($ Otolith weight $)-10.5 *(\text { Otolith weight })^{2}$.

554 Figure 5. Sex-specific and combined von Bertalanffy growth curves of (A) Lethrinus

555 xanthochilus, (B) Lutjanus gibbus, and (C) Lutjanus rufolineatus from Tutuila, American Samoa.

556 Solid lines represent best-fit curves for both sexes combined for each species. 
557 Figure 6. Distributions of total mortality $\left(Z, \mathrm{yr}^{-1}\right)$ from a length-stratified bootstrap resampling

558 procedure followed by multinomial catch curve analysis for (A) Lethrinus xanthochilus, (B)

559 Lutjanus gibbus, and (C) Lutjanus rufolineatus from the commercial fishery of Tutuila,

560 American Samoa.

561 Figure 7. Female maturation schedules by fork length fitted to maturity status data for (A)

562 Lethrinus xanthochilus, (B) Lutjanus gibbus, and (C) Lutjanus rufolineatus from Tutuila,

563 American Samoa. Age-based female maturation schedules were also derived for (D) Lethrinus

564 xanthochilus and (E) Lutjanus gibbus. In (D-E), white bars represent the proportion of immature

565 females, grey bars represent the proportion of mature females, and numbers above bars represent

566 age-specific sample sizes. For all plots, solid lines represent best-fit models and dotted lines

567 represent $95 \%$ confidence limits.

568 Figure 8. Photomicrographs of a $39 \mathrm{~cm}$ fork length (6 years old) Lethrinus xanthochilus with

569 preliminary evidence of postmaturational female-to-male sex change. Panels A and B are from

570 the same individual. AVO, atretic vitellogenic oocyte; GW, gonad wall; EP, rounded folds of the

571 epithelium; SM, spermatogenic material.

572 Figure 9. Photomicrographs of a potentially bisexual Lethrinus xanthochilus $(24 \mathrm{~cm}$ fork length,

5732 years old). GW, gonad wall; PO, primary oocyte; OL, ovarian lumen; ST, stromal tissue; SC,

574 potential sperm crypt development. 
Figure 1

Length-frequency distrbutions derived from the Tutuila-based, American Samoa commercial fishery from 2011-2015 for (A) Lethrinus xanthochilus, (B) Lutjanus gibbus, and (C) Lutjanus rufolineatus.

Total number of samples recorded are presented for each species.
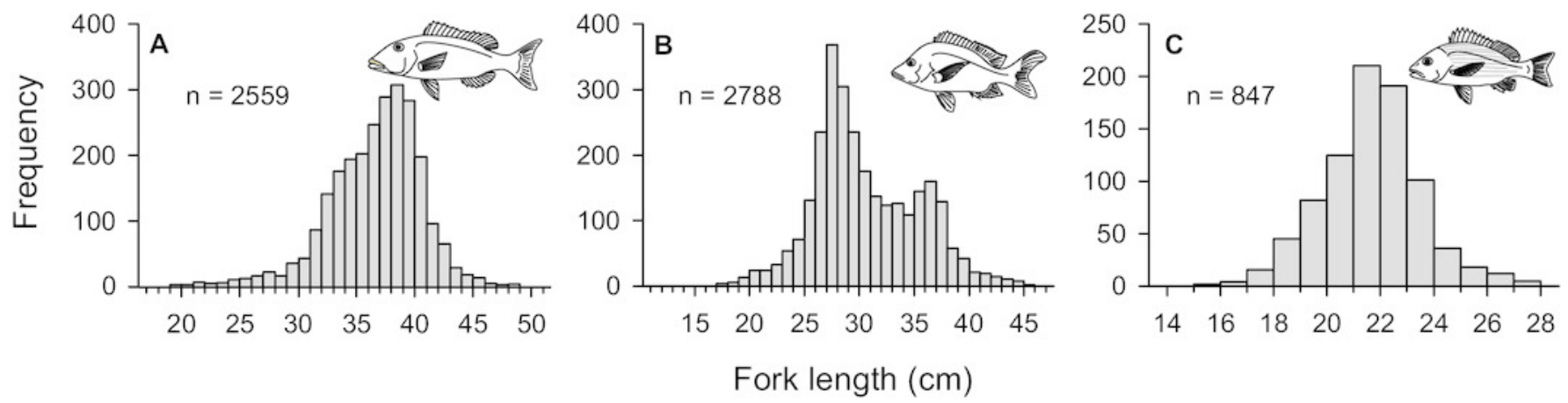
Figure 2

Frequency of opaque edge deposition by month in transverse sections of otoliths from three commercial species from Tutuila, American Samoa.

The continuous blue line displays mean daily sea surface temperature across the calendar year based on satellite-derived data from Jan 2006 to May 2011.

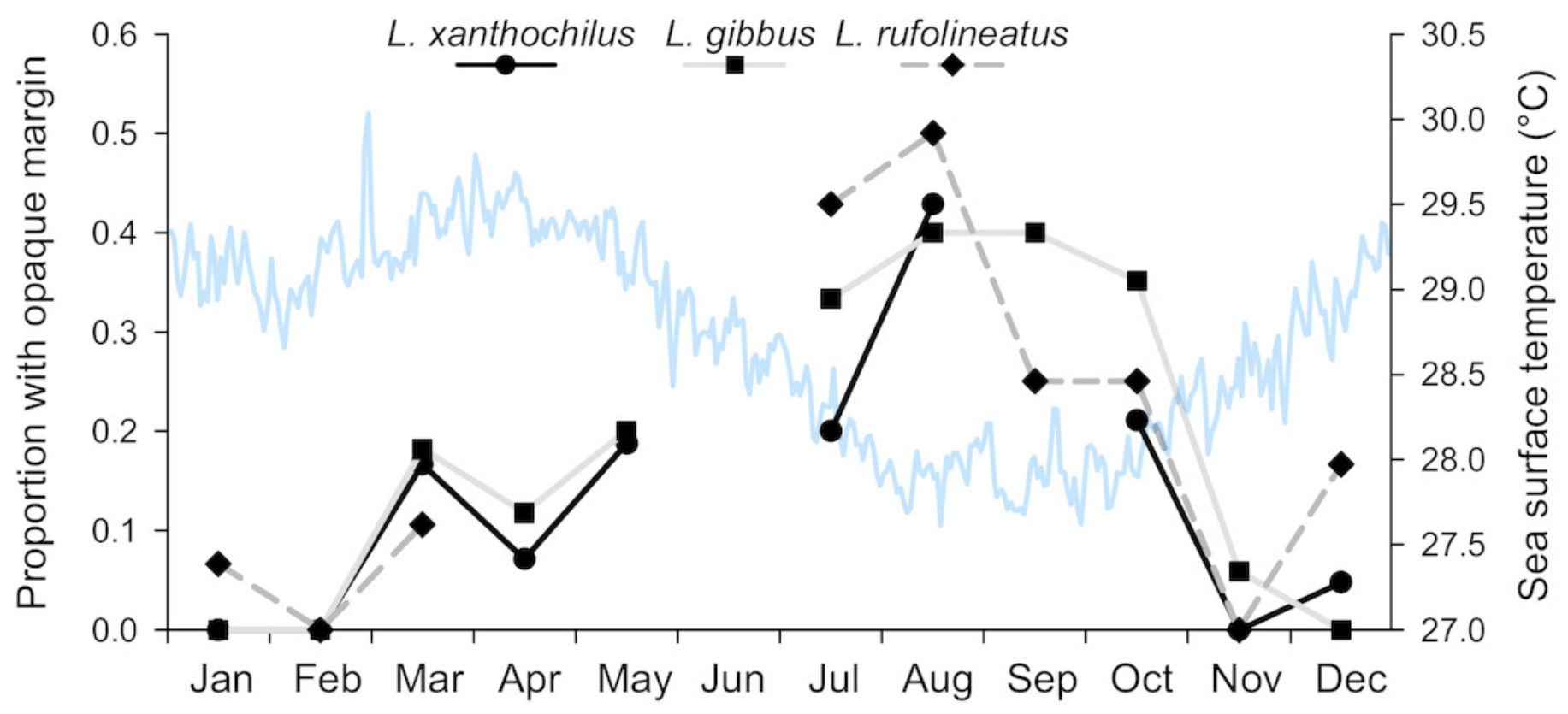




\section{Figure 3}

Photomicrographs of transverse otolith sections for $(A)$ Lethrinus xanthochilus (reflected light), (B) Lutjanus gibbus (transmitted light), and (C) Lutjanus rufolineatus (transmitted light).

Annual increments (opaque bands) are denoted by white boxes, with the inset in (B) providing greater resolution for smaller increments.
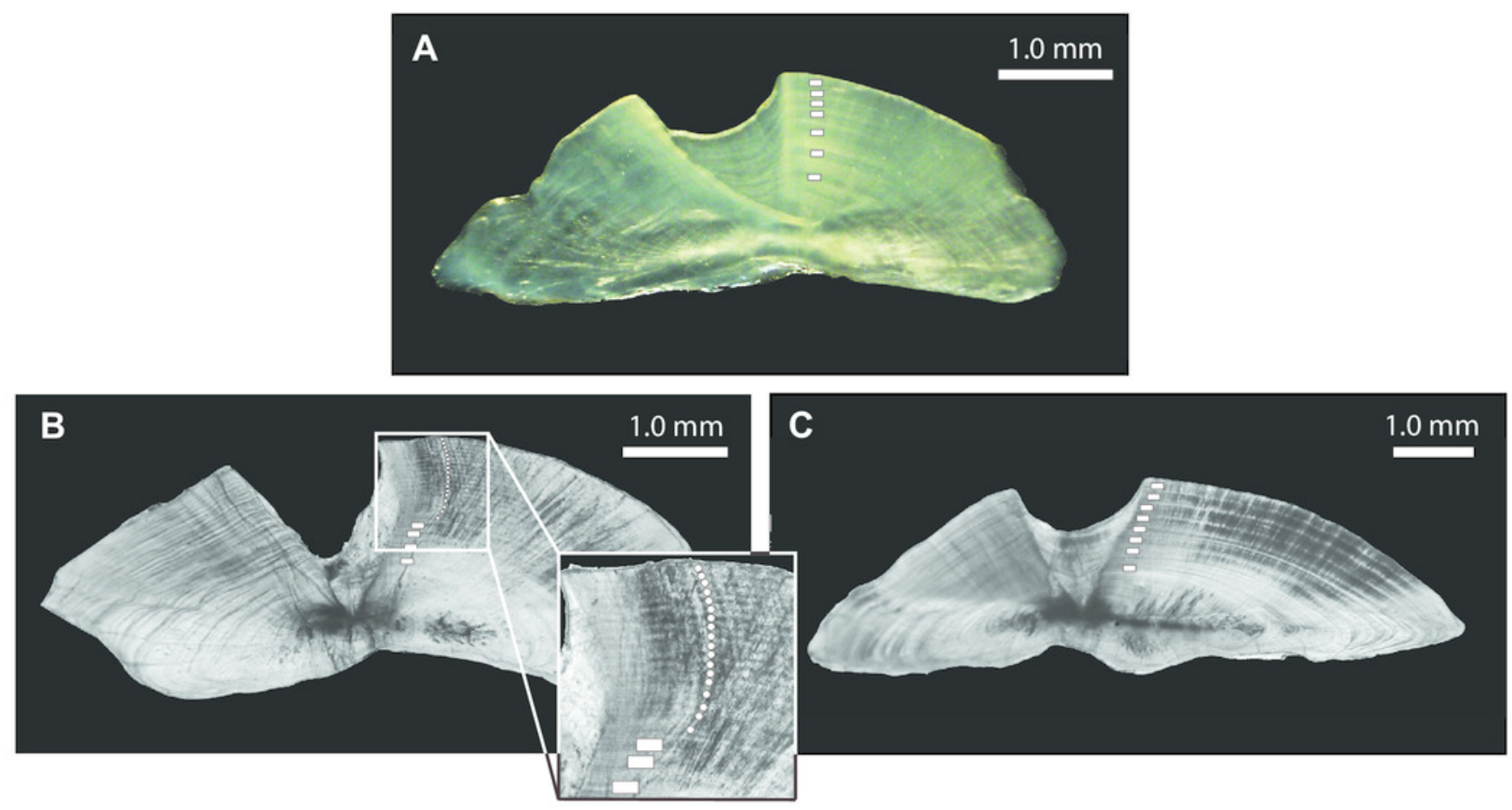


\section{Figure 4}

Sex-specific relationships between sagittal otolith weight $(\mathrm{g})$ and annual age (as number of annuli) for (A) Lethrinus xanthochilus, (B) Lutjanus gibbus, and (C) Lutjanus rufolineatus from Tutuila, American Samoa.

Equations are as follows: L. xanthochilus, male age $=0.3+20.2 *$ (Otolith weight) + $247.3^{*}(\text { Otolith weight })^{2}$, female age $=0.9+11.8 *($ Otolith weight $)+253.2 *(\text { Otolith weight })^{2}$;

L. gibbus, male age $=0.5+27.0 *$ (Otolith weight $)+444.0 *(\text { Otolith weight })^{2}$, female age $=-$ $0.5+47.4 *$ (Otolith weight) $+130.3 *$ (Otolith weight) ${ }^{2} ;$ L. rufolineatus, male age $=-1.0+$ $25.8 *($ Otolith weight $)+21.1 *(\text { Otolith weight })^{2}$, female age $=-1.1+33.1 *($ Otolith weight $)-$ $10.5 *$ (Otolith weight) ${ }^{2}$.
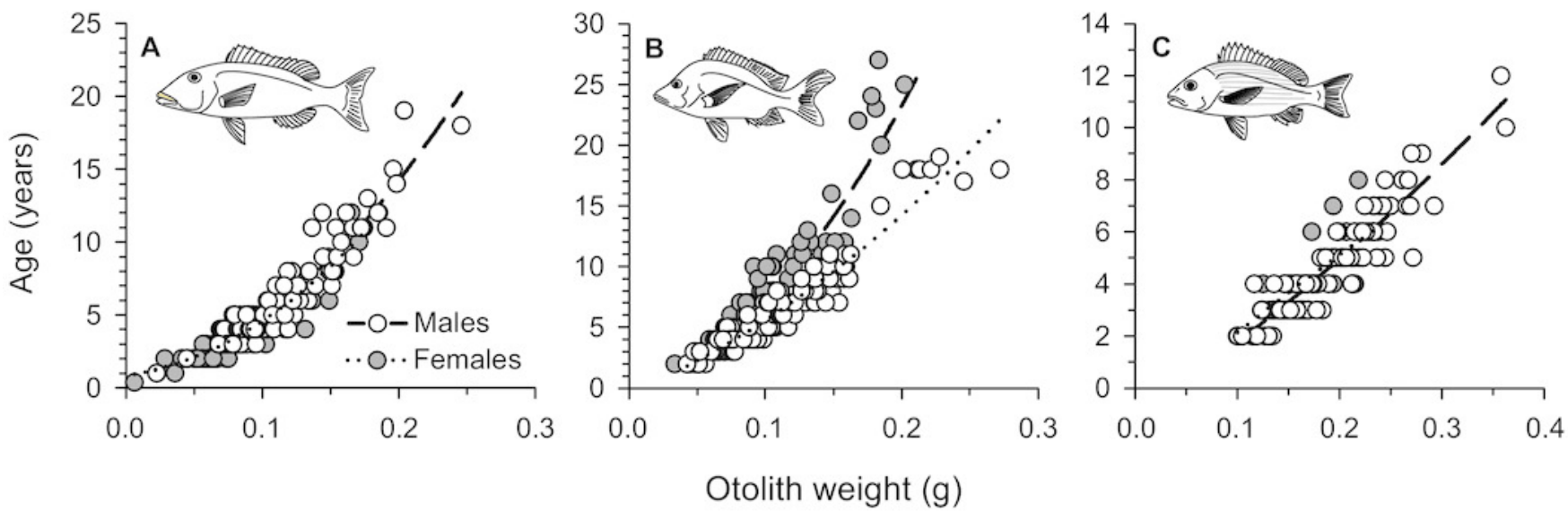
Figure 5

Sex-specific and combined von Bertalanffy growth curves of (A) Lethrinus xanthochilus, (B) Lutjanus gibbus, and (C) Lutjanus rufolineatus from Tutuila, American Samoa.

Solid lines represent best-fit curves for both sexes combined for each species.
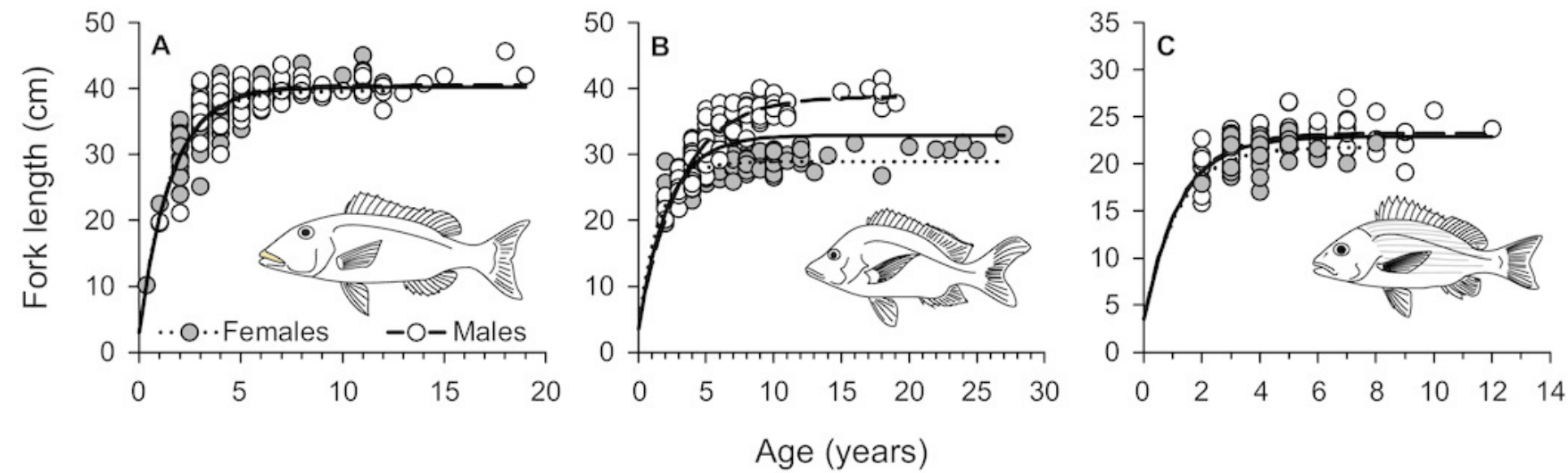
Figure 6

Distributions of total mortality $\left(Z, \mathrm{yr}^{-1}\right)$ from a length-stratified bootstrap resampling procedure followed by multinomial catch curve analysis

Distributions of total mortality $(Z, y r-1)$ from a length-stratified bootstrap resampling procedure followed by multinomial catch curve analysis for (A) Lethrinus xanthochilus, (B) Lutjanus gibbus, and (C) Lutjanus rufolineatus from the commercial fishery of Tutuila, American Samoa.
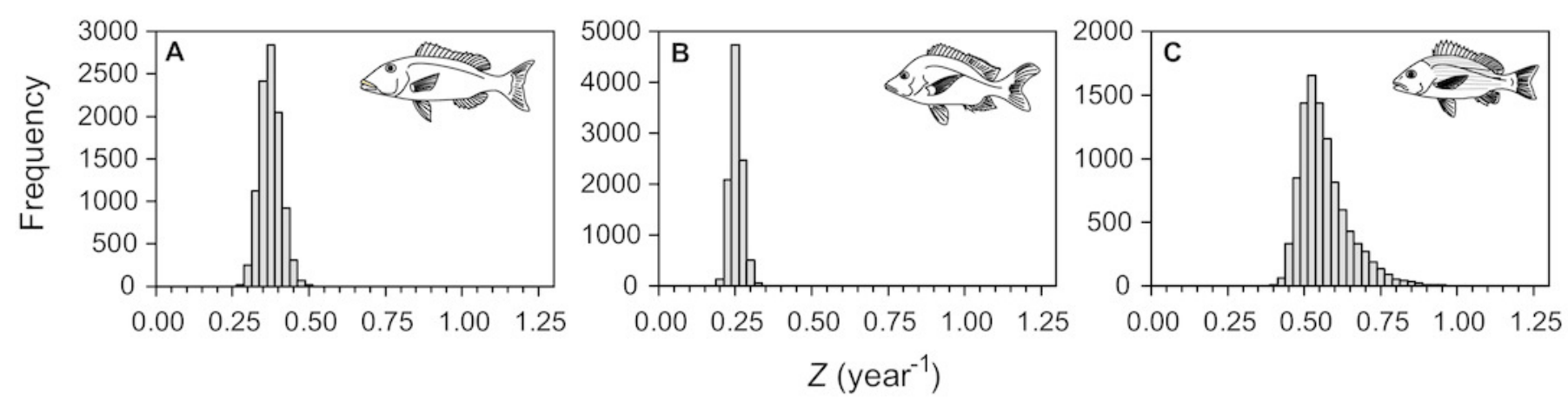
Figure 7

Female maturation schedules by fork length fitted to maturity status data for $(A)$ Lethrinus xanthochilus, (B) Lutjanus gibbus, and (C) Lutjanus rufolineatus from Tutuila, American Samoa.

Age-based female maturation schedules were also derived for (D) Lethrinus xanthochilus and (E) Lutjanus gibbus. In (D-E), white bars represent the proportion of immature females, grey bars represent the proportion of mature females, and numbers above bars represent agespecific sample sizes. For all plots, solid lines represent best-fit models and dotted lines represent $95 \%$ confidence limits.
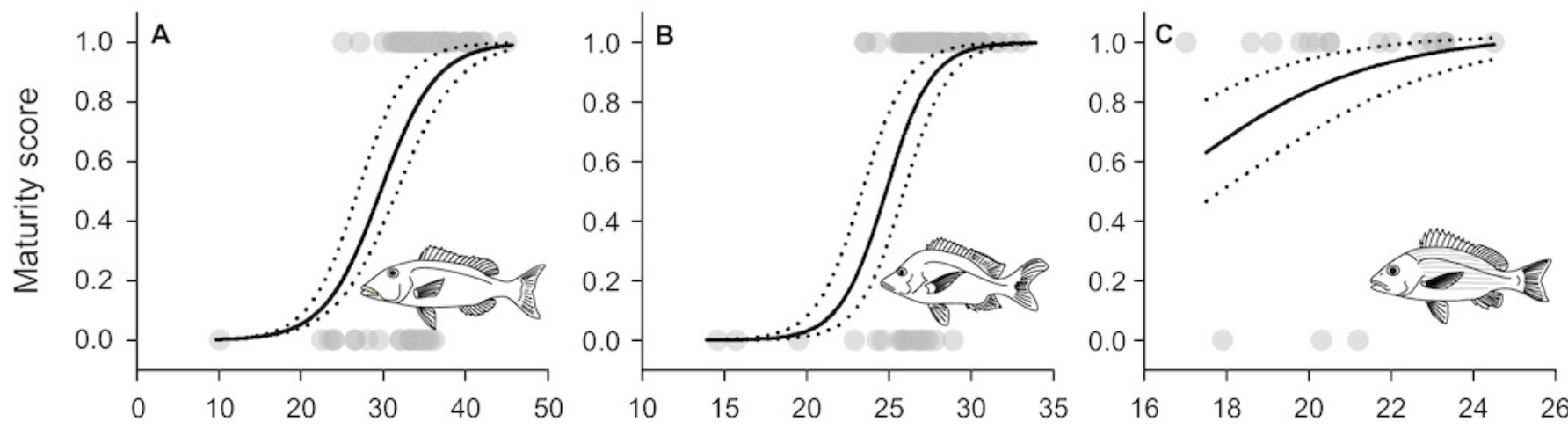

Fork length $(\mathrm{cm})$
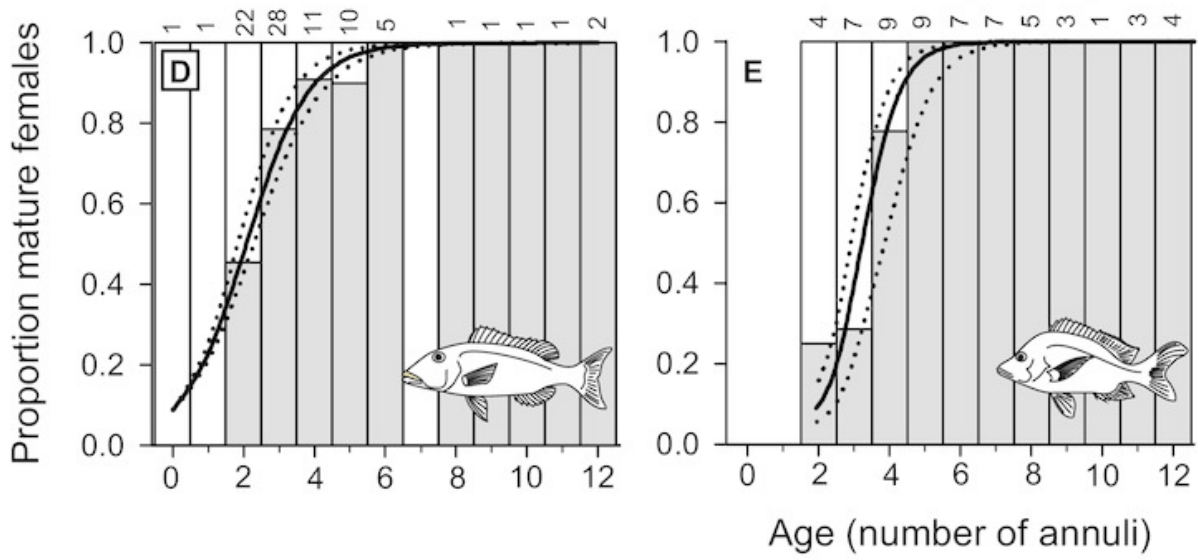
Figure 8

Photomicrographs of a $39 \mathrm{~cm}$ fork length (6 years old) Lethrinus xanthochilus with preliminary evidence of postmaturational female-to-male sex change.

Panels A and B are from the same individual. AVO, atretic vitellogenic oocyte; GW, gonad wall; EP, rounded folds of the epithelium; SM, spermatogenic material.

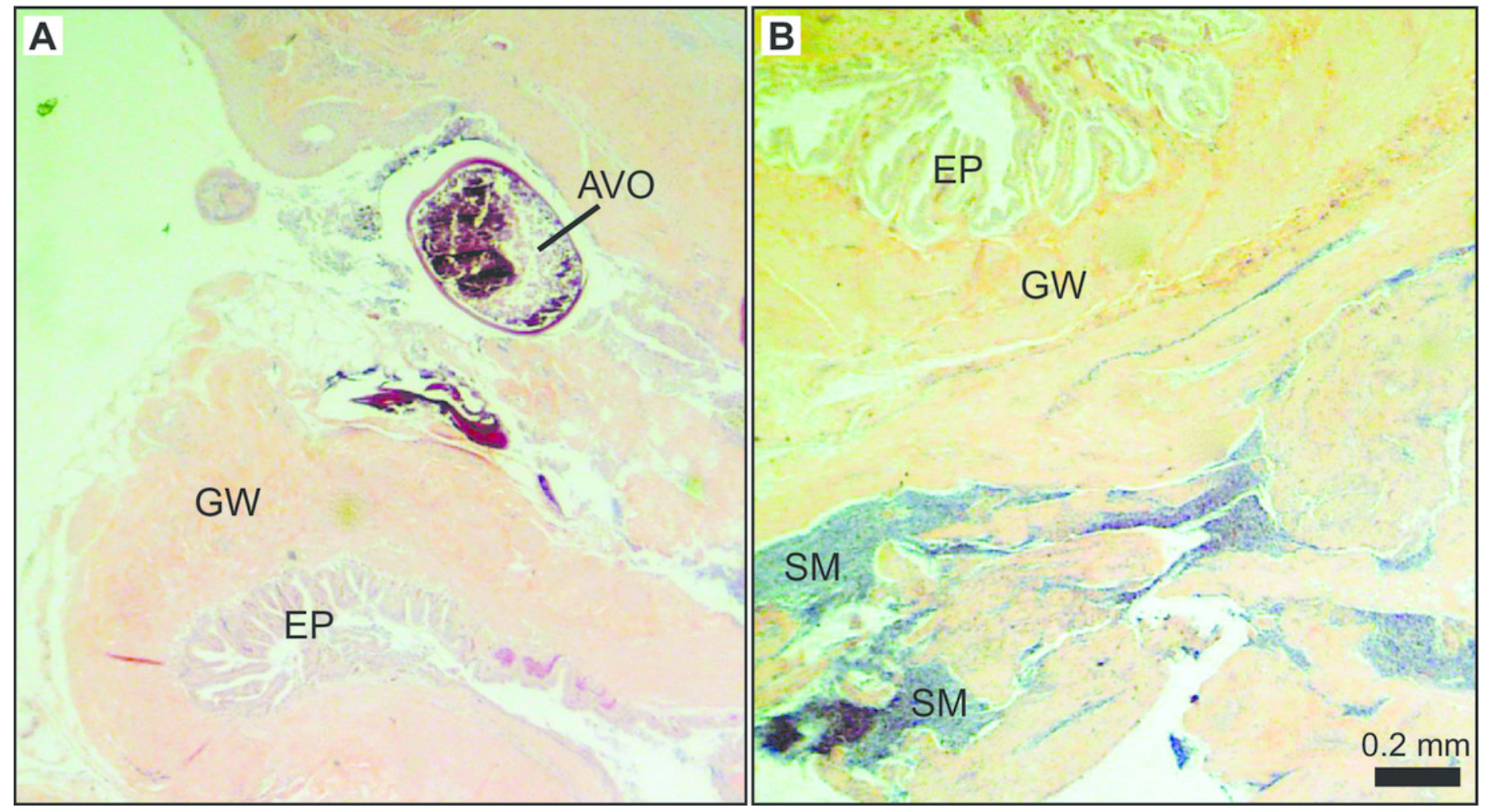


Figure 9

Photomicrographs of a potentially bisexual Lethrinus xanthochilus $(24 \mathrm{~cm}$ fork length, 2 years old).

GW, gonad wall; PO, primary oocyte; OL, ovarian lumen; ST, stromal tissue; SC, potential sperm crypt development.

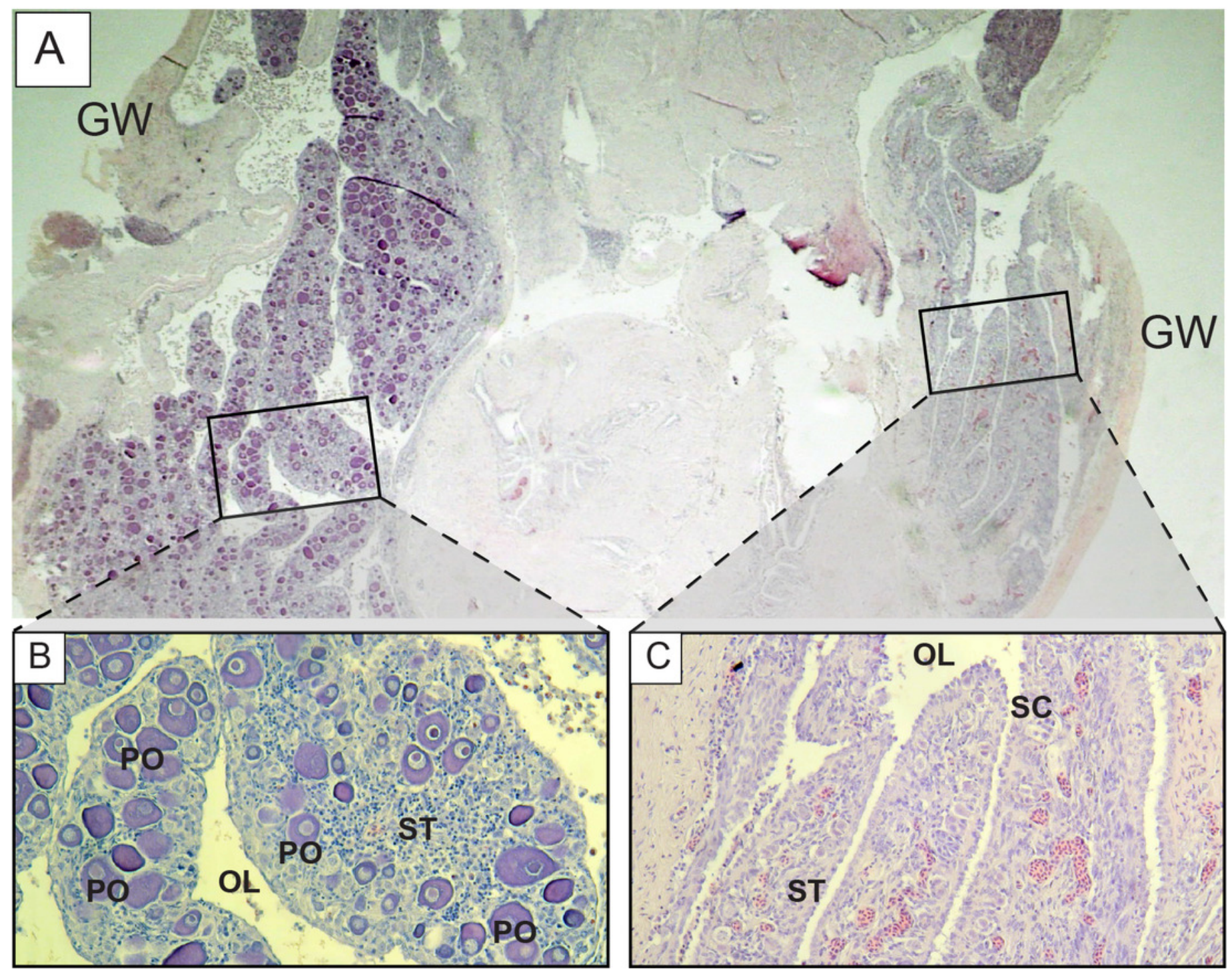




\section{Table $\mathbf{1}$ (on next page)}

Summary of life-history trait estimates for three commercially harvested species from American Samoa.

Associated 95\% confidence intervals are presented in parentheses where appropriate. 
$295 \%$ confidence intervals are presented in parentheses where appropriate.

\begin{tabular}{|c|c|c|c|c|c|c|c|c|c|}
\hline & \multicolumn{3}{|c|}{ Lethrinus xanthochilus } & \multicolumn{3}{|c|}{ Lutjanus gibbus } & \multicolumn{3}{|c|}{ Lutjanus rufolineatus } \\
\hline & Males & Females & Combined & Males & Females & Combined & Males & Females & Combined \\
\hline$L_{\infty}(\mathrm{cm})$ & $\begin{array}{c}40.5 \\
(39.7-41.3)\end{array}$ & $\begin{array}{c}39.6 \\
(38.3-40.9\end{array}$ & $\begin{array}{c}40.2 \\
(39.5-40.9)\end{array}$ & $\begin{array}{c}38.8 \\
(37.6-40.1)\end{array}$ & $\begin{array}{c}28.9 \\
(28.4-29.4)\end{array}$ & $\begin{array}{c}32.9 \\
(25.9-37.9)\end{array}$ & $\begin{array}{c}23.3 \\
(22.7-23.9)\end{array}$ & $\begin{array}{c}21.8 \\
(20.8-22.9)\end{array}$ & $\begin{array}{c}22.9 \\
(22.4-23.5)\end{array}$ \\
\hline$K\left(\mathrm{yr}^{-1}\right)$ & $\begin{array}{c}0.63 \\
(0.56-0.72)\end{array}$ & $\begin{array}{c}0.67 \\
(0.59-0.76)\end{array}$ & $\begin{array}{c}0.64 \\
(0.59-0.69)\end{array}$ & $\begin{array}{c}0.32 \\
(0.29-0.35)\end{array}$ & $\begin{array}{c}0.66 \\
(0.58-0.79)\end{array}$ & $\begin{array}{c}0.46 \\
(0.20-0.73)\end{array}$ & $\begin{array}{c}0.80 \\
(0.69-0.96)\end{array}$ & $\begin{array}{c}0.86 \\
(0.64-1.18)\end{array}$ & $\begin{array}{c}0.82 \\
(0.70-0.99)\end{array}$ \\
\hline$t_{0}(\mathrm{yr})$ & -0.12 & -0.12 & -0.12 & -0.29 & -0.19 & -0.25 & -0.20 & -0.20 & -0.20 \\
\hline$n$ aged & 98 & 137 & 236 & 119 & 117 & 236 & 105 & 29 & 134 \\
\hline$L_{50}(\mathrm{~cm})$ & - & $\begin{array}{c}30.0 \\
(27.3-31.8)\end{array}$ & - & - & $\begin{array}{c}24.9 \\
(23.5-25.8)\end{array}$ & - & - & $\begin{array}{c}16.4 \\
(14.6-18.1)\end{array}$ & - \\
\hline$L_{95}(\mathrm{~cm})$ & - & $\begin{array}{c}39.9 \\
(35.9-43.9)\end{array}$ & - & - & $\begin{array}{c}29.0 \\
(27.5-30.4)\end{array}$ & - & - & $\begin{array}{c}23.5 \\
(21.2-25.9)\end{array}$ & - \\
\hline$t_{50}(\mathrm{~cm})$ & - & $\begin{array}{c}2.1 \\
(1.8-2.3)\end{array}$ & - & - & $\begin{array}{c}3.2 \\
(2.9-3.9)\end{array}$ & - & - & - & - \\
\hline$t_{95}(\mathrm{~cm})$ & - & $\begin{array}{c}4.7 \\
(4.1-5.1)\end{array}$ & - & - & $\begin{array}{c}4.8 \\
(4.5-5.8)\end{array}$ & - & - & - & - \\
\hline$Z\left(\mathrm{yr}^{-1}\right)$ & - & - & $\begin{array}{c}0.35 \\
(0.29-0.41)\end{array}$ & - & - & $\begin{array}{c}0.22 \\
(0.19-0.26)\end{array}$ & - & - & $\begin{array}{c}0.54 \\
(0.44-0.75)\end{array}$ \\
\hline$M\left(\mathrm{yr}^{-1}\right)$ & - & - & 0.22 & - & - & 0.15 & - & - & 0.35 \\
\hline
\end{tabular}

3 Notes. $L_{\infty}$, asymptotic length; $K$, growth coefficient; $t_{0}$, hypothetical age when length equals zero; $n$ aged, number of specimens used

4 in age analysis; $L_{50}$, length at $50 \%$ sexual maturity; $L_{95}$, length at $95 \%$ sexual maturity; $t_{50}$, age at $50 \%$ sexual maturity; $t_{95}$, age at $95 \%$

5 sexual maturity; $Z$, instantaneous total mortality rate estimated from the logistic multinomial catch curve; $M$, natural mortality rate

6 estimated from Hoenig's (1983) method. 